\title{
Risk factors for acquisition of multidrug-resistant Escherichia coli and development of community-acquired urinary tract infections
}

\author{
U. V. UKAH ${ }^{1}$, M. GLASS ${ }^{2}$, B. AVERY ${ }^{3}$, D. DAIGNAULT ${ }^{4}$, M. R. MULVEY ${ }^{5,6}$, \\ R. J. REID-SMITH ${ }^{3,7}$, E. J. PARMLEY ${ }^{3}$, A. PORTT ${ }^{8}$, P. BOERLIN ${ }^{9}$ AND \\ A. R. MANGES ${ }^{2,10 *}$ \\ ${ }^{1}$ Department of Obstetrics and Gynaecology, University of British Columbia, Vancouver, BC, Canada \\ ${ }^{2}$ School of Population and Public Health, University of British Columbia, Vancouver, BC, Canada \\ ${ }^{3}$ Centre for Foodborne, Environmental and Zoonotic Infectious Diseases, Public Health Agency of Canada, \\ Guelph, ON, Canada \\ ${ }^{4}$ National Microbiology Laboratory, Public Health Agency of Canada, Saint-Hyacinthe, QC, Canada \\ ${ }^{5}$ Department of Medical Microbiology, University of Manitoba, Winnipeg, MB, Canada \\ ${ }^{6}$ National Microbiology Laboratory, Public Health Agency of Canada, Winnipeg, MB, Canada \\ ${ }^{7}$ Department of Population Medicine, University of Guelph, Ontario Veterinary College, Guelph, ON, Canada \\ ${ }^{8}$ The Research Institute of the McGill University Health Centre, Montréal, QC, Canada \\ ${ }^{9}$ Department of Pathobiology, University of Guelph, Guelph, ON, Canada \\ ${ }^{10}$ British Columbia Centre for Disease Control, Vancouver, BC, Canada
}

Final revision 3 October 2017; first published online 12 December 2017

\section{SUMMARY}

We examined risk factors associated with the intestinal acquisition of antimicrobial-resistant extraintestinal pathogenic Escherichia coli (ExPEC) and development of community-acquired urinary tract infection (UTI) in a case-control study of young women across Canada. A total of 399 women were recruited; 164 women had a UTI caused by E. coli resistant to $\geqslant 1$ antimicrobial classes and 98 had a UTI caused by $E$. coli resistant to $\geqslant 3$ antimicrobial classes. After adjustment for age, student health service (region of Canada) and either prior antibiotic use or UTI history, consumption of processed or ground chicken, cooked or raw shellfish, street foods and any organic fruit; as well as, contact with chickens, dogs and pet treats; and travel to Asia, were associated with an increased risk of UTI caused by antimicrobial resistant $E$. coli. A decreased risk of antimicrobial resistant UTI was associated with consumption of apples, nectarines, peppers, fresh herbs, peanuts and cooked beef. Drug-resistant UTI linked to foodborne and environmental exposures may be a significant public health concern and understanding the risk factors for intestinal acquisition of existing or newly emerging lineages of drug-resistant ExPEC is important for epidemiology, antimicrobial stewardship and prevention efforts.

Key words: Antimicrobial resistance, epidemiology, Escherichia coli, extraintestinal infections, extraintestinal pathogenic Escherichia coli, multidrug resistance, urinary tract infections.

\footnotetext{
* Author for correspondence: A. R. Manges, UBC, School of Population and Public Health, 137-2206 East Mall, Vancouver, BC V6T 1Z3, Canada.

(Email: amee.manges@ubc.ca)
}

\section{INTRODUCTION}

Extraintestinal pathogenic Escherichia coli (E. coli) or ExPEC are the major cause of extraintestinal infections (e.g., urinary tract and bloodstream infections) 
in humans [1, 2]. Half of all women will experience at least one urinary tract infection (UTI) during their lifetime [1]. ExPEC frequently exhibit resistance to one or more antimicrobial agents, making even uncomplicated UTIs challenging to manage. There is emerging evidence that the E. coli that cause extraintestinal infections in humans may have a food or food animal reservoir [3]. Outbreaks associated with ExPEC have been identified suggesting that a food or environmental source for ExPEC may exist [4]. In previous studies, chicken and pork have been identified as potential sources of ExPEC causing human UTIs [3, 5-7] and women who reported higher consumption of chicken and pork were more likely to develop multidrug-resistant infections [5]. Closely related groups of human ExPEC have been recovered from retail meats or directly from food animals at slaughter $[8,9]$. Although food is one possible source, ExPEC have also been identified in multiple nonhuman reservoirs, including companion animals, wastewater and other environmental sources [10].

Previous epidemiological studies have identified risk factors for the intestinal acquisition of ExPEC and development of extraintestinal infections. In one study of 290 subjects in Norway, development of a UTI caused by an extended spectrum $\beta$-lactamase-producing (ESBL) E. coli or Klebsiella pneumoniae was associated with travel to Asia, to the Middle East or Africa, exposure to fluroquinolones or $\beta$-lactam antibiotics, diabetes mellitus and freshwater swimming in the past year [11]. A second epidemiological study conducted in Pennsylvania, USA, including 165 cases of UTI caused by fluoroquinolone-resistant E. coli and 1836 controls who experienced a UTI caused by a fluoroquinolone-susceptible E. coli, found that Asian race, renal disease and previous exposure to nitrofurantoin were risk factors for fluoroquinolone-resistant UTI [12]. Other studies based on laboratory and clinical data have identified exposure to health care facilities and prior antimicrobial use as risk factors for antimicrobialresistant, community-acquired UTIs [13, 14].

The immediate source of the E. coli that cause extraintestinal infections is typically the individual's own intestinal tract. While intestinal colonisation does not lead to any immediate ill effects, $E$. coli are available to cause disease when risk factors for an extraintestinal infection occur. For example, the leading risk factor for UTI in young women is sexual intercourse. The mechanics of sexual intercourse facilitate the transfer of intestinal $E$. coli from the anus, across the perineum to the urethra and bladder leading to infection. The most significant challenge in determining the source of ExPEC intestinal acquisition and infection is the fact that extraintestinal infections may occur weeks or months after an ExPEC isolate has colonised the gut. Therefore, trace-back investigations, which are useful for identifying the source of diarrheal disease outbreaks (where disease develops within a few days), are of limited use in epidemiological investigations of food or environmental exposures to ExPEC due to the long lag between intestinal acquisition and infection.

To investigate the possible sources of drug-resistant ExPEC, we performed a case-control study. The primary hypothesis of this study is that more frequent consumption of poultry or poultry products is associated with an increased risk of UTI caused by an antimicrobial resistant (resistance to $\geqslant 1$ antimicrobial class) or multidrug-resistant (resistance to $\geqslant 3$ antimicrobial classes) $E$. coli. The study also examines other potential risk factors and exposures associated with the intestinal acquisition of ExPEC and development of antimicrobial resistant UTI.

\section{MATERIALS AND METHODS}

\section{Epidemiologic study design}

Women with UTI were recruited at five university student health services (SHSs) across Canada (Halifax, NS; Montreal, QC; Guelph, ON; Toronto, ON; Vancouver, BC). Research ethics boards at each SHS site approved the study; all participants provided their informed consent (UBC REB H11-03439). UTI was empirically defined as the presence of two or more symptoms, including dysuria, increased urinary frequency or urgency, pyuria and hematuria. If a woman had recurrent UTIs, only the isolate associated with the first infection during the study period was included. Women who reported being pregnant, being recently hospitalised, having any urogenital abnormality or diabetes were excluded from the study. Aliquots of urine from all consecutive urine specimens from women with suspected UTI at each SHS site were collected from October 2012 to May 2015 and shipped to the study laboratory. Urine was cultured on a biplate containing selective media (MacConkey/blood agar) (Orion Diagnostica Uricult, Finland). E. coli was re-plated on MacConkey and identification was confirmed using CHROMagar $^{\mathrm{TM}}$ MH Orientation (France) and by indole testing. A single colony was grown overnight in LB broth and then stored at $-80{ }^{\circ} \mathrm{C}$ in $15 \%$ glycerol. 
For the purposes of this case-control study, two sets of cases and controls were defined. In the first set, a case was defined as a woman with a UTI caused by an $E$. coli isolate resistant to $\geqslant 3$ or more classes of antimicrobial agents (termed multidrug-resistant or MDR) and controls were defined as a woman with a UTI caused by $E$. coli resistant to $\leqslant 2$ antimicrobial classes. In the second set, a case was defined as a woman with a UTI caused by $E$. coli resistant to $\geqslant 1$ antimicrobial classes (termed antimicrobial resistant) and controls were defined as women with UTI caused by an $E$. coli isolate susceptible to all antimicrobial classes.

\section{Risk factor questionnaire}

Women with suspected UTI recruited to the study completed a secure, online risk factor questionnaire. The questionnaire was devised partly based on the US Centres for Diseases Control, Foodborne Outbreak Response and Surveillance Unit Enteric Disease Hypothesis Generating Questionnaire from 2011 [15] and partly based on instruments used for nutritional assessments [16]. The questionnaire focussed on exposures that may be associated with the intestinal acquisition of $E$. coli or that have been linked to $E$. coli associated with foodborne outbreaks, including diet, travel history, water source and contact with animals or animal products. The questionnaire also included questions about health status (particularly history of UTI or other infections), recent use of antimicrobial agents, age and other factors. Women were asked to recall these exposures over a period of 30 days prior to the index UTI episode (the date for the UTI health care visit). Information on regular food consumption patterns and major dietary changes over the previous 6-months was also elicited. Women were asked to estimate their average consumption of each food item, food type or exposure according to the following scale: never, a few times a month, 1-3 days per week, 4-6 days per week, or every day. We linked the recovered E. coli isolate transferred from the SHS to questionnaire data for each study participant by using unique student identification numbers in combination with date of birth.

\section{Antimicrobial susceptibility testing}

All E. coli recovered from the SHSs were sent to the Public Health Agency of Canada, National Microbiology Laboratory, Saint-Hyacinthe, Québec for antimicrobial susceptibility testing. The minimum inhibitory concentration values for $E$. coli were determined by broth microdilution method (Clinical and Laboratory Standards Institute (CLSI) M7-A8) using an automated system (Sensititre ${ }^{\mathrm{TM}}$, Automated Microbiology System, Trek ${ }^{\mathrm{TM}}$ Diagnostic Systems Ltd, West Sussex, England) [17]. The CMV2AGNF plate (Sensititre ${ }^{\mathrm{TM}}$, Trek ${ }^{\mathrm{TM}}$ Diagnostic Systems Ltd, West Sussex, England) was designed by the US National Antimicrobial Resistance Monitoring System and contains a panel of 15 antimicrobials agents for susceptibility testing. Resistance to an antimicrobial class was defined as resistance to any of the following agents: aminoglycosides (gentamicin, streptomycin, kanamycin); cephalosporins (cefoxitin, ceftiofur, ceftriaxone); chloramphenicol; macrolides (azithromycin); penicillins (ampicillin, amoxicillin/clavulanic acid); quinolones (ciprofloxacin, nalidixic acid); sulfonamides (sulfisoxazole, trimethoprim/sulfamethoxazole); and tetracyclines (tetracycline) [17]. Intermediate susceptibility to any antimicrobial agent was classified as susceptible.

\section{Statistical analyses}

Risk factors were evaluated in univariable analyses with UTI caused by MDR E. coli (resistance to $\geqslant 3$ antimicrobial classes) or antimicrobial resistant $E$. coli (resistance to $\geqslant 1$ antimicrobial classes) as the outcome; odds ratios and $95 \%$ confidence intervals were estimated. We performed multiple logistic regression, for each variable significant by univariable analysis, including age, SHS and either number of lifetime UTIs or use of antimicrobials in the past 6 months. This was done to examine the independent effect of each exposure on drug-resistant UTI by adjusting for any influence of UTI history and prior antimicrobial exposure on increased drug-resistant $E$. coli carriage. As these two confounders are linked, separate multivariable models were run. We also examined risk factors associated with developing a UTI caused by $E$. coli resistant to any cephalosporin or any quinolone to compare our results with results from studies of extraintestinal infections caused by ESBL-positive and quinolone-resistant E. coli, although ESBL-production was not directly assessed. Exposure variables were grouped into (i) never (reference group), (ii) a few times a month or 1-3 days per week and (iii) 4 6 days per week or every day, based on distribution. In a few instances, responses were collapsed (at the high end of exposure) to ensure there was a minimum 
of 10 subjects total included in each comparison for the analyses. All analyses were conducted using the $\mathrm{R}$ statistical program (version 3.3.1).

\section{RESULTS}

\section{Study subjects}

From October 2012 to May 2015, 1677 Uricults were received from the SHSs and 1238 were positive for $E$. coli. A total of 733 unique women with suspected UTI from the five SHS were enrolled into the study and completed the online study questionnaire. Of these, 399 women completed the online questionnaire and had an E. coli isolate submitted to the study. SHSs were not able to submit urine specimens for each potential UTI case; furthermore, some women completed the survey, but bacterial concentrations in their urine were below detection and therefore these could not be included in the analyses.

In total 164 women $(41 \cdot 1 \%)$ had UTI caused by $E$. coli resistant to at least one antimicrobial class (antimicrobial resistant). Of these 164 women, 98 (24.6\%) experienced a UTI caused by $E$. coli resistant to $\geqslant 3$ antimicrobial classes (MDR). Characteristics of the women included in the final study sample are presented in Table 1. No significant differences in demographics (e.g., age, educational attainment or income) were observed between women with UTI caused by susceptible $v$ s. multidrug resistant E. coli, except for women with MDR UTI who reported a greater history of antimicrobial use in the past 6 months (OR $=1 \cdot 64 ; 95 \%$ confidence interval (CI) 1.02-2.55). These women also tended to have had a greater number of lifetime UTIs (Table 1). Detailed antimicrobial resistance information is provided in Table 2.

\section{Meat consumption or exposure associated with UTI caused by antimicrobial resistant $E$. coli}

Women who reported consumption of processed or ground chicken $\geqslant 1-3$ days per week were more likely to have a UTI caused by antimicrobial resistant $E$. coli $\left(\mathrm{OR}_{\text {adj }} 1 \cdot 58 ; 95 \%\right.$ CI 1.00-2.49), after adjusting for age, a SHS and antibiotic use (Table 3), but the odds ratio after adjusting for age, SHS and UTI history was elevated but not statistically significant $\left(\mathrm{OR}_{\text {adj }} 1 \cdot 61,95 \%\right.$ CI 0.93-2.79) (Table 4). Shellfish consumption exhibited a similar risk for antimicrobial resistant and MDR UTI $\left(\mathrm{OR}_{\mathrm{adj}}=1.95 ; 95 \%\right.$ CI $1 \cdot 20$ $3 \cdot 16$ and $\mathrm{OR}_{\mathrm{adj}}=2 \cdot 07 ; 95 \%$ CI $1 \cdot 22-3 \cdot 50$ ), after adjustment for prior antibiotic use (Table 3) and for UTI history (Table 4), respectively. There was an increased risk of MDR UTI in women who reported consumption of raw meat $(\mathrm{OR}=2 \cdot 15 ; 95 \%$ CI $1 \cdot 02$ $4 \cdot 50) \geqslant 1-3$ days per week vs. women who never ate raw meat in the univariable analyses; however, raw meat was not significant after adjustment for age and prior antibiotic use $\left(\mathrm{OR}_{\mathrm{adj}}=1.76 ; 95 \%\right.$ CI $0.81-$ $3 \cdot 83$ ) (Table 3) or after adjustment for age, SHS and lifetime UTIs $\left(\mathrm{OR}_{\mathrm{adj}}=2 \cdot 38 ; 95 \%\right.$ CI $\left.0.98-5 \cdot 78\right)$ (Table 4). Consumption of cooked ground beef $\geqslant 1-$ 3 days per week was associated with a lower risk of developing a UTI caused by E. coli resistant to at least one antimicrobial class $\left(\mathrm{OR}_{\mathrm{adj}}=0.61 ; 95 \% \mathrm{CI}\right.$ $0.39-0.98$ and $\mathrm{OR}_{\text {adj }}=0.56 ; 95 \%$ CI $0.33-0.95$ ) (Tables 3 and 4), after adjustment for antimicrobial use and UTI history, respectively. Consumption of pork or other meats was not associated with increased risk of antimicrobial resistant or MDR UTI, nor was there an association between the cooking method for whole beef or hamburger/ground beef (i.e. rare vs. medium or well cooked).

\section{Non-meat dietary exposures and UTI caused by antimicrobial resistant $E$. coli}

Consumption of organic fruits was associated with an increased risk of developing MDR UTI $\left(\mathrm{OR}_{\mathrm{adj}}=\right.$ 8.60; 95\% CI 1.11-66.53) after adjustment for age, SHS and antibiotic use, but not after adjustment for UTI history. However, an association with antimicrobial resistant UTI was present after adjustment for UTI history (Tables 3 and 4). More frequent consumption of street foods (e.g., food carts or food truck) was associated with antimicrobial resistant UTI $\left(\mathrm{OR}_{\mathrm{adj}}=\right.$ 1.66; 95\% CI 1.04-2.65) (Table 3). Foods prepared in the home, restaurants, or campus dining halls were not associated with a resistant UTI. Consumption of apples, nectarines, peanuts, fresh herbs and peppers were variably associated with a decreased risk of developing an antimicrobial resistant or MDR UTI after adjustment (Tables 3 and 4).

\section{Contact with animals, animal waste or pet products and risk of UTI caused by antimicrobial resistant $E$. coli}

Contact with live chickens (or chicken feces) was associated with a greater risk of developing a UTI caused by an E. coli resistant to at least one antimicrobial class $\left(\mathrm{OR}_{\mathrm{adj}}=3 \cdot 62 ; 95 \% \mathrm{CI} 1 \cdot 08-12 \cdot 10\right.$ and $\mathrm{OR}_{\mathrm{adj}}=$ 6.30; 95\% CI 1.26-31.51) after adjustment for age, 
Table 1. Characteristics of the study subjects

\begin{tabular}{|c|c|c|c|}
\hline Characteristics & $\begin{array}{l}\text { Women with UTI caused by } \\
\text { fully susceptible } E \text {. coli } \\
N=235\end{array}$ & $\begin{array}{l}\text { Women with UTI caused by } \\
E \text {. coli resistant to } \geqslant 1 \\
\text { antimicrobial classes } \\
N=164\end{array}$ & $\begin{array}{l}\text { Women with UTI caused by } \\
E . \text { coli resistant to } \geqslant 3 \\
\text { antimicrobial classes } \\
N=98\end{array}$ \\
\hline Mean age (range, s.D.) & $21 \cdot 8(18-34 ; 3 \cdot 41)$ & $21 \cdot 8(18-50 ; 3 \cdot 62)$ & $21.9(18-34 ; 3 \cdot 07)$ \\
\hline \multicolumn{4}{|l|}{ Number $(\%)$ by location } \\
\hline Vancouver, British Columbia & $70(29 \cdot 8)$ & $45(27 \cdot 4)$ & $28(28 \cdot 6)$ \\
\hline Guelph, Ontario & $86(36 \cdot 7)$ & $48(26 \cdot 3)$ & $31(31 \cdot 6)$ \\
\hline Halifax, Nova Scotia & $1(0 \cdot 43)$ & $4(2 \cdot 4)$ & $2(2 \cdot 0)$ \\
\hline Montréal, Québec & $60(25 \cdot 5)$ & $53(32 \cdot 3)$ & $33(33 \cdot 7)$ \\
\hline Toronto, Ontario & $18(7 \cdot 7)$ & $14(8 \cdot 5)$ & $4(4 \cdot 1)$ \\
\hline $\begin{array}{l}\text { Median UTIs over past } \\
12 \text { months (range, s.D.) }\end{array}$ & $1(0-8 ; 1 \cdot 53)$ & $1(0-10 ; 1 \cdot 52)$ & $1(0-10 ; 1 \cdot 63)$ \\
\hline $\begin{array}{l}\text { Median UTIs over lifetime } \\
\text { (range, s.D.) }\end{array}$ & $2(0-50 ; 4 \cdot 92)$ & $2(0-70 ; 7 \cdot 40)$ & $3(0-70 ; 8 \cdot 36)$ \\
\hline $\begin{array}{l}\text { Any diarrhoea in the past } \\
30 \text { days }(N, \%)\end{array}$ & $86(36 \cdot 6)$ & $70(42 \cdot 7)$ & $43(43 \cdot 9)$ \\
\hline $\begin{array}{l}\text { Any antimicrobial use in the } \\
\text { past } 6 \text { months }(\mathrm{N}, \%)\end{array}$ & $104(44 \cdot 3)$ & $76(46 \cdot 3)$ & $53(54 \cdot 1)^{*}$ \\
\hline $\begin{array}{l}\text { Any sexual intercourse in the } \\
\text { past } 30 \text { days }(N, \%)\end{array}$ & $221(94 \cdot 0)$ & $152(92 \cdot 7)$ & $91(92 \cdot 9)$ \\
\hline
\end{tabular}

* Odds ratio for any antimicrobial use in the past 6 months among those with UTI caused by MDR E. coli was 1.64 (95\%CI $1 \cdot 02-2 \cdot 55)$. The 98 women with MDR UTI are a subset of the 164 women with UTI caused by E. coli resistant to at least one class of antimicrobials.

Table 2. Antimicrobial resistance phenotype distribution

\begin{tabular}{ll}
\hline \hline & \\
Antimicrobial class resistance & $\begin{array}{l}\text { Isolates } \\
N(\%)\end{array}$ \\
\hline Total isolates & $399(100)$ \\
$\quad$ Aminoglycosides & $81(20 \cdot 3)$ \\
Cephalosporins & $14(3 \cdot 5)$ \\
Macrolides & $30(7 \cdot 5)$ \\
Penicillins & $129(32 \cdot 3)$ \\
Quinolones & $56(14 \cdot 0)$ \\
Sulfanomides & $95(23 \cdot 8)$ \\
Tetracycline & $79(19 \cdot 8)$ \\
Chloramphenicol & $15(3 \cdot 8)$ \\
Multidrug resistance & \\
$\geqslant 1$ class & $164(41 \cdot 1)$ \\
$\geqslant 3$ classes & $98(24 \cdot 6)$ \\
$\geqslant 5$ classes & $33(8 \cdot 3)$ \\
\hline \hline
\end{tabular}

Classes were defined as: aminoglycosides (gentamicin, streptomycin, kanamycin); cephalosporins (cefoxitin, ceftiofur, ceftriaxone); chloramphenicol; macrolides (azithromycin); penicillins (ampicillin, amoxicillin/clavulanic acid); quinolones (ciprofloxacin, nalidixic acid); sulfonamides (sulfizoxazole, trimethoprim/sulfamethoxazole); and tetracyclines (tetracycline).

SHS and prior antimicrobial use or UTI history (Tables 3 and 4). Contact with dogs (or dog feces) was associated with a UTI caused by a MDR $E$. coli isolate $\left(\mathrm{OR}_{\mathrm{adj}}=1 \cdot 74 ; 95 \%\right.$ CI $1.08-2 \cdot 80$ and $\mathrm{OR}_{\mathrm{adj}}=2 \cdot 23 ; 95 \% \mathrm{CI} 1 \cdot 29-3 \cdot 87$ ) after adjustment for prior antimicrobial use or UTI history, respectively. After adjustment for prior antimicrobial use, exposure to animal-derived pet treats was also associated with MDR UTI (Table 3).

\section{Travel and risk of UTI caused by antimicrobial resistant $E$. coli}

In univariable analyses, travel within Canada was associated with an elevated risk of antimicrobial resistant UTI (OR $=1 \cdot 50 ; 95 \%$ CI $0 \cdot 99-2 \cdot 24)$, while travel outside of Canada (OR $=1 \cdot 50 ; 95 \%$ CI 1.00-2.24), especially travel to Asia (OR $=2 \cdot 82 ; 95 \%$ CI $1 \cdot 20-6 \cdot 63$ ) was associated with a greater risk of MDR UTI. Travel to Asia remained elevated after adjusting for age, SHS and antibiotic use $\left(\mathrm{OR}_{\mathrm{adj}}=1.51 ; 95 \% \mathrm{CI}\right.$ $1 \cdot 0-2 \cdot 28)$, but was no longer significant following adjustment for age, SHS and lifetime UTI (Tables 3 and 4).

\section{Factors not associated with risk of UTI caused by antimicrobial resistant $E$. coli}

Other dietary variables not found to be associated with drug-resistant UTI included: alcohol consumption; vegetarianism; adhering to any special diet 
Table 3. Exposures associated with UTI caused by antimicrobial resistant and MDR E. coli adjusted for age, student health service* and prior antibiotic use

\begin{tabular}{|c|c|c|c|c|c|c|c|c|}
\hline \multirow[b]{2}{*}{ Variable } & \multirow[b]{2}{*}{ Frequency } & \multirow[b]{2}{*}{$\begin{array}{l}\text { Number } \\
\text { Exposed }\end{array}$} & \multicolumn{3}{|c|}{$\begin{array}{l}\text { Resistance to } \geqslant 1 \\
\text { antimicrobial class }\end{array}$} & \multicolumn{3}{|c|}{$\begin{array}{c}\text { Resistance to } \geqslant 3 \\
\text { antimicrobial classes }\end{array}$} \\
\hline & & & \multicolumn{3}{|c|}{$\begin{array}{c}\text { Adjusted } \\
\text { Odds Ratio 95\% CI }\end{array}$} & \multicolumn{3}{|c|}{$\begin{array}{c}\text { Adjusted } \\
\text { Odds Ratio 95\% CI }\end{array}$} \\
\hline \multicolumn{9}{|l|}{ Poultry } \\
\hline \multirow[t]{3}{*}{ Whole cut chicken } & Never & 62 & Reference & & & Reference & & \\
\hline & $\leqslant 1-3$ days per week & 277 & 0.84 & 0.48 & 1.48 & 0.84 & 0.44 & 1.60 \\
\hline & $>4-6$ days per week & 59 & 1.16 & 0.55 & 2.45 & 1.29 & 0.56 & 2.96 \\
\hline \multirow[t]{2}{*}{ Processed or ground chicken } & Never & 278 & Reference & & & Reference & & \\
\hline & $\geqslant 1-3$ days per week & 117 & 1.58 & 1.00 & 2.49 & 1.18 & 0.70 & 1.98 \\
\hline \multirow[t]{2}{*}{ Breaded chicken strips } & Never & 221 & Reference & & & Reference & & \\
\hline & $\geqslant 1-3$ days per week & 177 & 1.10 & 0.71 & 1.69 & 1.01 & 0.61 & 1.65 \\
\hline \multirow[t]{3}{*}{ Turkey } & Never & 184 & Reference & & & Reference & & \\
\hline & $\leqslant 1-3$ days per week & 203 & 0.96 & 0.63 & 1.46 & 0.82 & 0.51 & 1.32 \\
\hline & $>4-6$ days per week & 11 & 1.80 & 0.52 & 6.12 & 0.58 & 0.12 & 2.80 \\
\hline \multicolumn{9}{|l|}{ Seafood } \\
\hline \multirow[t]{2}{*}{ Cooked or raw shellfish } & Never & 307 & Reference & & & Reference & & \\
\hline & $\geqslant 1-3$ days per week & 92 & 1.95 & 1.20 & 3.16 & 2.07 & 1.22 & 3.50 \\
\hline \multicolumn{9}{|l|}{ Other Meat } \\
\hline \multirow[t]{2}{*}{ Raw meat } & Never & 366 & Reference & & & Reference & & \\
\hline & $\geqslant 1-3$ days per week & 33 & 0.94 & 0.44 & 1.99 & 1.76 & 0.81 & 3.83 \\
\hline \multirow[t]{2}{*}{ Cooked ground beef } & Never & 100 & Reference & & & Reference & & \\
\hline & $\geqslant 1-3$ days per week & 298 & 0.61 & 0.39 & 0.98 & 0.65 & 0.39 & 1.09 \\
\hline \multirow[t]{3}{*}{ Whole beef cooked } & Rare & 57 & Reference & & & Reference & & \\
\hline & Medium & 119 & 0.49 & 0.25 & 0.97 & 0.62 & 0.29 & 1.36 \\
\hline & Well done & 59 & 1.24 & 0.57 & 2.67 & 0.85 & 0.35 & 2.11 \\
\hline \multicolumn{9}{|l|}{ Fruit } \\
\hline Any organic fruit & Never & 21 & Reference & & & Reference & & \\
\hline & $\leqslant 1-3$ days per week & 152 & 2.85 & 0.99 & 8.23 & 8.60 & 1.11 & 66.53 \\
\hline & $>4-6$ days per week & 44 & 2.49 & 0.77 & 8.07 & 7.77 & 0.93 & 61.13 \\
\hline Apples & Never & 40 & Reference & & & Reference & & \\
\hline & $\leqslant 1-3$ days per week & 285 & 0.44 & 0.22 & 0.87 & 0.63 & 0.30 & 1.33 \\
\hline & $>$ 4-6 days per week & 74 & 0.61 & 0.27 & 1.34 & 0.73 & 0.31 & 1.74 \\
\hline Nectarines & Never & 310 & Reference & & & Reference & & \\
\hline & $\geqslant 1-3$ days per week & 86 & 0.58 & 0.35 & 0.98 & 0.50 & 0.26 & 0.95 \\
\hline Vegetables & & & & & & & & \\
\hline Fresh herbs & Never & 127 & Reference & & & Reference & & \\
\hline & $\leqslant 1-3$ days per week & 235 & 0.57 & 0.36 & 0.90 & 0.55 & 0.33 & 0.92 \\
\hline & $>$ 4-6 days per week & 35 & 1.01 & 0.47 & 2.18 & 0.89 & 0.36 & 2.08 \\
\hline Peppers & Never & 50 & Reference & & & Reference & & \\
\hline & $\leqslant 1-3$ days per week & 279 & 0.65 & 0.35 & 1.20 & 0.74 & 0.37 & 1.48 \\
\hline & $>4-6$ days per week & 69 & 0.38 & 0.17 & 0.83 & 0.56 & 0.23 & 1.36 \\
\hline Fresh beans & Never & 199 & Reference & & & Reference & & \\
\hline & $\leqslant 1-3$ days per week & 187 & 0.67 & 0.44 & 1.02 & 0.74 & 0.46 & 1.21 \\
\hline & $>4-6$ days per week & 11 & 0.43 & 0.11 & 1.69 & 0.58 & 0.12 & 2.85 \\
\hline Nuts & & & & & & & & \\
\hline Peanut & Never & 206 & Reference & & & Reference & & \\
\hline & $\geqslant 1-3$ days per week & 192 & 0.77 & 0.51 & 1.16 & 0.58 & 0.38 & 0.94 \\
\hline Pecans & Never & 295 & Reference & & & Reference & & \\
\hline & $\geqslant 1-3$ days per week & 102 & 0.69 & 0.42 & 1.12 & 0.55 & 0.30 & 1.02 \\
\hline Eating locations & & & & & & & & \\
\hline Street cart/Food truck & Never & 297 & Reference & & & Reference & & \\
\hline & $\geqslant 1-3$ days per week & 101 & 1.66 & 1.04 & 2.65 & 1.29 & 0.76 & 2.20 \\
\hline
\end{tabular}


Table 3 (cont.)

\begin{tabular}{|c|c|c|c|c|c|c|c|c|}
\hline \multirow[b]{2}{*}{ Variable } & \multirow[b]{2}{*}{ Frequency } & \multirow[b]{2}{*}{$\begin{array}{l}\text { Number } \\
\text { Exposed }\end{array}$} & \multicolumn{3}{|c|}{$\begin{array}{l}\text { Resistance to } \geqslant 1 \\
\text { antimicrobial class }\end{array}$} & \multicolumn{3}{|c|}{$\begin{array}{c}\text { Resistance to } \geqslant 3 \\
\text { antimicrobial classes }\end{array}$} \\
\hline & & & \multicolumn{3}{|c|}{$\begin{array}{c}\text { Adjusted } \\
\text { Odds Ratio } 95 \% \text { CI }\end{array}$} & \multicolumn{3}{|c|}{$\begin{array}{c}\text { Adjusted } \\
\text { Odds Ratio 95\% CI }\end{array}$} \\
\hline \multicolumn{9}{|l|}{ Travel history } \\
\hline \multirow{2}{*}{ Travel within CA in past 6 months } & No & 230 & Reference & & & Reference & & \\
\hline & Yes & 169 & 1.32 & 0.84 & 2.07 & 1.41 & 0.83 & 2.37 \\
\hline \multirow[t]{2}{*}{ Travel outside CA in past 6 months } & No & 189 & Reference & & & Reference & & \\
\hline & Yes & 210 & 1.43 & 0.94 & 2.19 & 1.42 & 0.86 & 2.32 \\
\hline \multirow{2}{*}{ Travel to Asia } & No & 189 & Reference & & & Reference & & \\
\hline & Yes & 26 & 1.51 & 1.00 & 2.28 & 1.51 & 0.95 & 2.41 \\
\hline \multicolumn{9}{|l|}{ Animal (or animal feces) contact } \\
\hline \multirow[t]{2}{*}{ Chicken } & No & 386 & Reference & & & Reference & & \\
\hline & Yes & 13 & 3.62 & 1.08 & 12.10 & 2.10 & 0.65 & 6.79 \\
\hline \multirow[t]{2}{*}{ Dogs } & No & 220 & Reference & & & Reference & & \\
\hline & Yes & 179 & 1.62 & 1.07 & 2.44 & 1.74 & 1.08 & 2.80 \\
\hline \multicolumn{9}{|l|}{ Pet food or treats } \\
\hline \multirow[t]{2}{*}{ Animal-derived pet treats } & Never & 346 & Reference & & & Reference & & \\
\hline & $\geqslant 1-3$ days per week & 52 & 1.65 & 0.92 & 2.99 & 2.35 & 1.23 & 4.49 \\
\hline
\end{tabular}

Odds ratios are adjusted; bold indicates $95 \%$ confidence limits that exclude 1.0$)$. ${ }^{*}$ The Nova Scotia site was excluded from the multivariable models, as the number of subjects $(n=5)$ was small. Results for all meat related exposures assessed on the questionnaire are included as meat consumption was the primary hypothesis of the study. Otherwise, only those exposures associated with an antimicrobial resistant or MDR UTI in the univariable analyses are presented.

(e.g., Kosher); organic foods (except fruit); antibioticfree foods; any significant diet changes; conventional fruits (melon, pears, peaches, apricots, plums, citrus fruits, any berries, grapes, bananas, exotic fruits, dried fruits, avocados, unpasteurised juices); nuts (almonds, cashews, hazelnuts, peanut butter, pistachios, walnuts); vegetables (tomatoes, salsa, leafy greens, sprouts, cabbage, cucumbers, zucchini, celery, carrots, radishes, peas, broccoli, cauliflower, onions, scallions, mushrooms, water chestnuts, vegetable juices); and unpasteurised cheese, raw or undercooked eggs; eating at fast food or sit-down restaurants, delis, home prepared meals and campus dining halls. The frequency of sexual intercourse was not associated with a drug-resistant infection, nor was the type of housing (e.g., dormitory, family home, apartment, communal housing) or a number of individuals sharing a kitchen. Animal-related exposures such as dry pet food, raw meat pet food, rodents or processed pet chews were not associated with antimicrobial resistant UTI; nor was exposure to cats, cattle, fish, goats, horses, pigs, reptiles, rodents, turkeys, or other birds. Travel to Mexico, Central and South America, or Africa was not associated with experiencing any drug-resistant UTI.

\section{DISCUSSION}

Consumption of poultry, in this case, processed or ground chicken and contact with chickens were associated with an increased risk of developing UTI caused by antimicrobial resistant E. coli. However, there was no indication that exposure to whole cut chicken, chicken strips or turkey was associated with the development of a UTI caused by either antimicrobial resistant or MDR E. coli. These results provide partial support for our primary study hypothesis and complement observations from other studies, which have implicated chicken as a possible reservoir for drug-resistant ExPEC [5, 7-9]. We did not observe any relationships between pork consumption and antimicrobial resistant or MDR UTI, nor ampicillin or cephalosporin-resistant $E$. coli in this study; in contradiction to our earlier observations [5].

Consumption of several high-risk foods was associated with antimicrobial resistant and MDR UTI, including consumption of cooked or raw shellfish, raw meat and street foods. Seafood has been reported to be an important reservoir for antimicrobial resistant opportunistic pathogens and may increase the risk of drug-resistant infections [18-21]. Organic fruit consumption was also associated with an 
Table 4. Exposures associated with UTI caused by antimicrobial resistant $\mathrm{E}$. coli adjusted for age, student health service* and UTI history

\begin{tabular}{|c|c|c|c|c|c|c|c|c|}
\hline \multirow[b]{2}{*}{ Variable } & \multirow[b]{2}{*}{ Frequency } & \multirow[b]{2}{*}{$\begin{array}{l}\text { Number } \\
\text { Exposed }\end{array}$} & \multicolumn{3}{|c|}{$\begin{array}{l}\text { Resistance to } \geqslant 1 \\
\text { antimicrobial class }\end{array}$} & \multicolumn{3}{|c|}{$\begin{array}{c}\text { Resistance to } \geqslant 3 \\
\text { antimicrobial classes }\end{array}$} \\
\hline & & & \multicolumn{3}{|c|}{$\begin{array}{c}\text { Adjusted } \\
\text { Odds Ratio } 95 \% \text { CI }\end{array}$} & \multicolumn{3}{|c|}{$\begin{array}{c}\text { Adjusted } \\
\text { Odds Ratio 95\% CI }\end{array}$} \\
\hline \multicolumn{9}{|l|}{ Poultry } \\
\hline \multirow[t]{3}{*}{ Whole cut chicken } & Never & 62 & Reference & & & Reference & & \\
\hline & $\leqslant 1-3$ days per week & 277 & 0.92 & 0.48 & 1.75 & 1.10 & 0.52 & 2.32 \\
\hline & $>4-6$ days per week & 59 & 1.26 & 0.53 & 2.98 & 2.40 & 0.93 & 6.22 \\
\hline \multirow[t]{2}{*}{ Processed or ground chicken } & Never & 278 & Reference & & & Reference & & \\
\hline & $\geqslant 1-3$ days per week & 117 & 1.61 & 0.93 & 2.79 & 1.18 & 0.64 & 2.12 \\
\hline \multirow[t]{2}{*}{ Breaded chicken strips } & Never & 221 & Reference & & & Reference & & \\
\hline & $\geqslant 1-3$ days per week & 177 & 1.18 & 0.71 & 1.96 & 1.14 & 0.65 & 2.02 \\
\hline \multirow[t]{3}{*}{ Turkey } & Never & 184 & Reference & & & Reference & & \\
\hline & $\leqslant 1-3$ days per week & 203 & 0.80 & 0.49 & 1.30 & 0.75 & 0.44 & 1.30 \\
\hline & $>4-6$ days per week & 11 & 1.93 & 0.40 & 1.94 & 1.02 & 0.19 & 5.62 \\
\hline \multicolumn{9}{|l|}{ Seafood } \\
\hline \multirow[t]{2}{*}{ Cooked or raw shellfish } & Never & 307 & Reference & & & Reference & & \\
\hline & $\geqslant 1-3$ days per week & 92 & 1.76 & 1.00 & 3.10 & 1.81 & 0.98 & 3.32 \\
\hline \multicolumn{9}{|l|}{ Other meat } \\
\hline \multirow[t]{2}{*}{ Raw meat } & Never & 366 & Reference & & & Reference & & \\
\hline & $\geqslant 1-3$ days per week & 33 & 1.49 & 0.62 & 3.58 & 2.38 & 0.98 & 5.78 \\
\hline \multirow[t]{2}{*}{ Cooked ground beef } & Never & 100 & Reference & & & Reference & & \\
\hline & $\geqslant 1-3$ days per week & 298 & 0.56 & 0.33 & 0.95 & 0.62 & 0.34 & 1.07 \\
\hline \multirow[t]{3}{*}{ Whole beef cooked } & Rare & 57 & Reference & & & Reference & & \\
\hline & Medium & 119 & 0.61 & 0.28 & 1.30 & 0.92 & 0.39 & 2.15 \\
\hline & Well done & 59 & 1.37 & 0.54 & 3.49 & 1.17 & 0.42 & 3.24 \\
\hline \multicolumn{9}{|l|}{ Fruit } \\
\hline \multirow[t]{3}{*}{ Any organic fruit } & Never & 21 & Reference & & & Reference & & \\
\hline & $\leqslant 1-3$ days per week & 152 & 5.69 & 1.18 & 27.60 & 5.86 & 0.72 & 47.44 \\
\hline & $>4-6$ days per week & 44 & 3.75 & 0.69 & 20.28 & 4.36 & 0.48 & 39.44 \\
\hline \multirow[t]{3}{*}{ Apples } & Never & 40 & Reference & & & Reference & & \\
\hline & $\leqslant 1-3$ days per week & 285 & 0.34 & 0.15 & 0.76 & 0.49 & 0.22 & 1.09 \\
\hline & $>4-6$ days per week & 74 & 0.51 & 0.21 & 1.27 & 0.64 & 0.25 & 1.62 \\
\hline Nectarines & Never & 310 & Reference & & & Reference & & \\
\hline & $\geqslant 1-3$ days per week & 86 & 0.62 & 0.34 & 1.15 & 0.59 & 0.29 & 1.19 \\
\hline Vegetables & & & & & & & & \\
\hline Fresh herbs & Never & 127 & Reference & & & Reference & & \\
\hline & $\leqslant 1-3$ days per week & 235 & 0.51 & 0.30 & 0.89 & 0.50 & 0.28 & 0.90 \\
\hline & $>4-6$ days per week & 35 & 1.03 & 0.43 & 2.48 & 0.62 & 0.23 & 1.65 \\
\hline Peppers & Never & 50 & Reference & & & Reference & & \\
\hline & $\leqslant 1-3$ days per week & 279 & 0.52 & 0.25 & 1.08 & 0.69 & 0.32 & 1.51 \\
\hline & $>4-6$ days per week & 69 & 0.26 & 0.10 & 0.68 & 0.36 & 0.13 & 1.05 \\
\hline Fresh beans & Never & 199 & Reference & & & Reference & & \\
\hline & $\leqslant 1-3$ days per week & 187 & 0.68 & 0.42 & 1.11 & 0.67 & 0.38 & 1.15 \\
\hline & $>4-6$ days per week & 11 & 0.71 & 0.15 & 3.38 & 0.69 & 0.13 & 3.81 \\
\hline Nuts & & & & & & & & \\
\hline Peanut & Never & 206 & Reference & & & Reference & & \\
\hline & $\geqslant 1-3$ days per week & 192 & 0.70 & 0.44 & 1.14 & 0.51 & 0.28 & 0.90 \\
\hline Pecans & Never & 295 & Reference & & & Reference & & \\
\hline & $\geqslant 1-3$ days per week & 102 & 0.62 & 0.35 & 1.09 & 0.53 & 0.27 & 1.04 \\
\hline
\end{tabular}


Table 4 (cont.)

\begin{tabular}{|c|c|c|c|c|c|c|c|c|}
\hline \multirow[b]{2}{*}{ Variable } & \multirow[b]{2}{*}{ Frequency } & \multirow[b]{2}{*}{$\begin{array}{l}\text { Number } \\
\text { Exposed }\end{array}$} & \multicolumn{3}{|c|}{$\begin{array}{l}\text { Resistance to } \geqslant 1 \\
\text { antimicrobial class }\end{array}$} & \multicolumn{3}{|c|}{$\begin{array}{c}\text { Resistance to } \geqslant 3 \\
\text { antimicrobial classes }\end{array}$} \\
\hline & & & \multicolumn{3}{|c|}{$\begin{array}{c}\text { Adjusted } \\
\text { Odds Ratio } 95 \% \text { CI }\end{array}$} & \multicolumn{3}{|c|}{$\begin{array}{c}\text { Adjusted } \\
\text { Odds Ratio } 95 \% \text { CI }\end{array}$} \\
\hline \multicolumn{9}{|l|}{ Travel history } \\
\hline \multirow[t]{2}{*}{ Travel within CA in past 6 months } & No & 230 & Reference & & & Reference & & \\
\hline & Yes & 169 & 1.31 & 0.76 & 2.23 & 1.35 & 0.74 & 2.45 \\
\hline \multirow[t]{2}{*}{ Travel outside CA in past 6 months } & No & 189 & Reference & & & Reference & & \\
\hline & Yes & 210 & 1.32 & 0.81 & 2.17 & 1.12 & 0.64 & 1.93 \\
\hline \multirow[t]{2}{*}{ Travel to Asia } & No & 189 & Reference & & & Reference & & \\
\hline & Yes & 210 & 1.56 & 0.94 & 2.60 & 1.25 & 0.70 & 2.21 \\
\hline \multicolumn{9}{|l|}{ Eating locations } \\
\hline \multirow[t]{2}{*}{ Street cart/Food truck } & Never & 297 & Reference & & & Reference & & \\
\hline & $\geqslant 1-3$ days per week & 101 & 1.47 & 0.85 & 2.54 & 1.27 & 0.70 & 2.30 \\
\hline \multicolumn{9}{|l|}{ Animal (or animal feces) contact } \\
\hline \multirow[t]{2}{*}{ Chicken } & No & 386 & Reference & & & Reference & & \\
\hline & Yes & 13 & 6.30 & 1.26 & 31.51 & 3.07 & 0.76 & 12.44 \\
\hline \multirow[t]{2}{*}{ Dogs } & No & 220 & Reference & & & Reference & & \\
\hline & Yes & 179 & 1.88 & 1.15 & 3.07 & 2.23 & 1.29 & 3.87 \\
\hline \multicolumn{9}{|l|}{ Pet food or treats } \\
\hline \multirow[t]{2}{*}{ Animal-derived pet treats } & Never & 346 & Reference & & & Reference & & \\
\hline & $\geqslant 1-3$ days per week & 52 & 1.79 & 0.82 & 3.60 & 2.01 & 0.93 & 4.36 \\
\hline
\end{tabular}

Odds ratios are adjusted; bold indicates $95 \%$ confidence limits that exclude 1.0). *The Nova Scotia site was excluded from the multivariable models, as the number of subjects $(n=5)$ was small. Results for all meat related exposures assessed on the questionnaire are included as meat consumption was the primary hypothesis of the study. Otherwise, only those exposures associated with an antimicrobial resistant or MDR UTI in the univariable analyses are presented.

increased risk of MDR UTI. This may be the result of waste products used as fertilisers in organic farming [22]. An antimicrobial effect of pesticides or nonorganic fertilisers could be a possible explanation, although this is an untested hypothesis.

Increased risk of MDR UTI with exposure to dogs and pet treats (which may or may not contain meat products) is not surprising given the prior associations of drug-resistant ExPEC in companion animals and associated family members [23-27].

Self-reported Asian race or travel to Asia have been reported to be risk factors for antimicrobialresistant ExPEC infections in past studies [11, 12, 28]. Travel to Asia was identified as a significant risk factor for MDR UTI development in our study. Increased prevalence and diversity of antimicrobial resistant ExPEC in Asia has been demonstrated in several community-based studies of colonisation and extraintestinal infection and in returning travellers [28-33]. In contrast to these studies, we did not observe any associations between developing a UTI caused by E. coli resistant to any cephalosporin or any quinolone and dietary intake,
Asian race, swimming, recent antibiotic use, kidney infection, or travel history $[11,12]$.

Peanuts, fresh herbs, peppers, apples and nectarines were observed to be 'protective' against antimicrobialresistant UTI. The mechanism for this effect, if true, is unclear. We explored the consumptions of these 'protective' foods by racial/ethnic groups but did not observe any significant differences (data not shown). These 'protective' factors may reflect confounding due to their relationship to other behaviours associated with a lower risk of drug-resistant UTI or greater overall health. Consumption of cooked ground beef $\geqslant 1-3$ days per week was associated with a lower risk of antimicrobial resistant UTI; these relationships may reflect certain preferences for beef over poultry or reflect food handling and preparation practices. Retail beef typically has the lowest levels of antimicrobial resistant generic E. coli contamination (compared with retail pork and poultry meats) [34-36].

The strengths of this study include a large sample of women with uncomplicated, community-acquired UTI. The sample included all consecutive UTI cases willing to participate in the study without bias due 
to clinical laboratory screening algorithms or by selective inclusion of women with relapsing or recurrent infections. Exposure information was systematically collected on all risk factors likely to be associated with the intestinal acquisition of ExPEC. Direct intestinal acquisition of antimicrobial ExPEC was not measured in this study. We elected to study E. coli recovered from cases of UTI, rather than $E$. coli intestinal colonisation alone, because we wanted to be sure to capture $E$. coli that can cause extraintestinal infections. There is a consensus that the primary source for E. coli associated with community-acquired UTIs is the intestinal tract of infected individuals [37]. There are several limitations to the study. Subjects whose UTI-causing $E$. coli were classified as susceptible or resistant to fewer than 2 classes of antimicrobials may still have been intestinally colonised by another MDR ExPEC strain. The result of this misclassification would be to underestimate the odds ratios estimated in this study. An outbreak investigation-like case-control approach was used to address our primary hypothesis and to investigate exposures that may put individuals at risk of antimicrobial resistant UTI, which, by definition, means multiple comparisons were made. Therefore, some of these observed relationships are likely to be false positives. In some instances, statistical adjustment for confounding by age and SHS, and either antimicrobial use or UTI history led to attenuation in our effect estimates. We were not able to explore in detail the role of other healthcare contact as a potential confounder, nor were we able to collect detailed information on timing or location of exposures. Women who did not complete the survey may have differed systematically from the women who did participate, contributing to a selection bias.

In response to increases in antimicrobial-resistant UTI incidence, we sought to investigate the relationship between the consumption of meat, especially chicken, as well as other environmental exposures and the development of antimicrobial resistant or MDR UTI caused by E. coli. The use of antibiotics for treatment, prophylaxis and growth promotion in food animals can select for antimicrobial resistant enteric pathogens [3]. It would be a serious concern if certain antimicrobial use practices in food animal production also contribute to the selection of antimicrobial resistant $E$. coli causing UTI or other extraintestinal infections (e.g., pyelonephritis or bloodstream infections) in humans. Our study suggests that specific high-risk foods, including processed poultry meat, travel and contact with chickens and dogs may be associated with the acquisition of antimicrobial-resistant ExPEC. Given the breadth of environmental exposures related to antimicrobial UTI highlighted this study, the focus on antimicrobial stewardship in human clinical medicine alone will not be sufficient to manage the growing level of antimicrobial resistance in community-acquired infections. Rather multi-sectoral stewardship approaches including veterinary medicine, food animal production, produce farming practices and global cooperation to control the ecologic proliferation and selection of antimicrobial resistant ExPEC will be necessary for public health.

\section{ACKNOWLEDGEMENTS}

This work was supported by the Canadian Institutes of Health Research (CIHR), Institute of Infection and Immunity (MOP-114879) and the Public Health Agency of Canada to A.R.M.

\section{DECLARATION OF INTEREST}

None to declare.

\section{ETHICAL STANDARDS}

The authors assert that all procedures contributing to this work comply with the ethical standards of the relevant national and institutional committees on human experimentation and with the Helsinki Declaration of 1975, as revised in 2008.

\section{REFERENCES}

1. Foxman B. Epidemiology of urinary tract infections: incidence, morbidity, and economic costs. American Journal of Medicine 2002; 113: 5S-13S.

2. Russo TA, Johnson JR. Medical and economic impact of extraintestinal infections due to Escherichia coli: focus on an increasingly important endemic problem. Microbes and Infection 2003; 5: 449-456.

3. Nordstrom L, Liu CM, Price LB. Foodborne urinary tract infections: a new paradigm for antimicrobialresistant foodborne illness. Frontiers in Microbiology 2013; 4: 1-6.

4. George DB, Manges AR. A systematic review of outbreak and non-outbreak studies of extraintestinal pathogenic Escherichia coli causing community-acquired infections. Epidemiology and Infection 2010; 138: 1679-1690.

5. Manges AR, et al. Retail meat consumption and the acquisition of antimicrobial resistant Escherichia coli 
causing urinary tract infections: a case-control study. Foodborne Pathogens and Disease 2007; 4: 419-431.

6. Manges AR, Johnson JR. Food-borne origins of Escherichia coli causing extraintestinal infections. Clinical Infectious Diseases 2013; 55: 712-719.

7. Leverstein-van Hall MA, et al. Dutch patients, retail chicken meat and poultry share the same ESBL genes, plasmids and strains. Clinical Microbiology and Infection 2011; 17: 873-880.

8. Vincent C, et al. Food reservoir for Escherichia coli causing urinary tract infections. Emerging Infectious Diseases 2010; 16: 88-95.

9. Bergeron CR, et al. Chicken as reservoir for extraintestinal pathogenic Escherichia coli in humans, Canada. Emerging Infectious Diseases 2012; 18: 415-421.

10. Johnson JR, Manges AR. Reservoirs of extraintestinal pathogenic Escherichia coli. Microbiology Spectrum 2015; 3, doi:10.1128/microbiolspec.UTI-0006-2012.

11. Soraas A, et al. Risk factors for community-acquired urinary tract infections caused by ESBL-producing Enterobacteriaceae: a case-control study in a low prevalence country. PLOS ONE 2013; 8: 1-7.

12. Rattanaumpawan $\mathbf{P}$, et al. Risk factors for ambulatory urinary tract infections caused by high-MIC fluoroquinolone-susceptible Escherichia coli in women: results from a large case-control study. Journal of Antimicrobial Chemotherapy 2014; 70: 1547-1551.

13. Steinke DT, et al. Prior trimethoprim use and trimethoprim-resistant urinary tract infection: a nested case-control study with multivariate analysis for other risk factors. Journal of Antimicrobial Chemotherapy 2001; 47: 781-787.

14. Ikram R, et al. An outbreak of multi-drug resistant Escherichia coli urinary tract infection in an elderly population: a case-control study of risk factors. $B M C$ Infectious Diseases 2015; 15: 224-231.

15. Centers for Disease Control and Prevention. Foodborne Disease Outbreak Investigation and Surveillance Tools (http://www.cdc.gov/foodsafety/outbreaks/surveillancereporting/investigation-toolkit.html). Accessed 8 November 2011.

16. Boucher B, et al. Validity and reliability of the Block 98 food-frequency questionnaire in a sample of Canadian women. Public Health Nutrition 2006; 9: 84-93.

17. Government of Canada Public Health Agency of Canada. Canadian Integrated Program for Antimicrobial Resistance Surveillance (CIPARS). Annual Report 2013, Guelph, Ontario.

18. Janecko N, et al. Carbapenem-resistant Enterobacter spp. In retail seafood imported from Southeast Asia to Canada. Emerging Infectious Diseases 2016; 22: 1675-1677.

19. Iwamoto M, et al. Epidemiology of seafood-associated infections in the United States. Clinical Microbiology Reviews 2010; 23: 399-411.

20. Morrison BJ, Rubin JE. Carbapenemase producing bacteria in the food supply escaping detection. PLoS ONE 2015; 10: 1-7.

21. Rubin JE, Ekanayake S, Fernando C. Carbapenemaseproducing organism in food, 2014. Emerging Infectious Diseases 2014; 20: 1264-1265.
22. Ruimy R, et al. Organic and conventional fruits and vegetables contain equivalent counts of gram-negative bacteria expressing resistance to antibacterial agents. Environmental Microbiology 2010; 12: 608-615.

23. Johnson JR, Clabots C. Sharing of virulent Escherichia coli clones among household members of a woman with acute cystitis. Clinical Infectious Diseases 2006; 43: e101-e118.

24. Johnson JR, Stell AL, Delavari P. Canine feces as a reservoir of extraintestinal pathogenic Escherichia coli. Infection and Immunity 2001; 69: 1306-1314.

25. Ewers C, et al. Emergence of human pandemic O25: H4-ST131 CTX-M-15 extended-spectrum-beta-lactamase-producing Escherichia coli among companion animals. Journal of Antimicrobial Chemotherapy 2010; 65: 651-660.

26. Guardabassi L, Schwarz S, Lloyd DH. Pet animals as reservoirs of antimicrobial-resistant bacteria: review. Journal of Antimicrobial Chemotherapy 2004; 54: 321332.

27. Platell JL, et al. Commonality among fluoroquinoloneresistant sequence type ST131 extraintestinal Escherichia coli isolates from humans and companion animals in Australia. Antimicrobial Agents and Chemotherapy 2011; 55: 3782-3787.

28. Peirano G, et al. Travel-related carbapenemaseproducing gram-negative bacteria in Alberta, Canada: the first 3 years. Journal of Clinical Microbiology 2014; 52: $1575-1581$.

29. Dyar OJ, et al. High prevalence of antibiotic resistance in commensal Escherichia coli among children in rural Vietnam. BMC Infectious Diseases 2012; 12: 92.

30. Lübbert $\mathbf{C}$, et al. Colonization with extended-spectrum beta-lactamase-producing and carbapenemaseproducing Enterobacteriaceae in international travelers returning to Germany. International Journal of Medical Microbiology 2015; 305: 148-156.

31. Nicolas-Chanoine MH, et al. Intercontinental emergence of Escherichia coli clone O25:H4-ST131 producing CTX-M-15. Journal of Antimicrobial Chemotherapy 2011; 61: 273-281.

32. Peirano G, Schreckenberger PC, Pitout JDD. Characteristics of NDM-1-producing Escherichia coli isolates that belong to the successful and virulent clone ST131. Antimicrobial Agents and Chemotherapy 2011; 55: 2986-2988.

33. Jakobsen L, et al. An ST405 NDM-4-producing Escherichia coli isolated from a Danish patient previously hospitalized in Vietnam. Journal of Antimicrobial Chemotherapy 2014; 69: 559-560.

34. Public Health Agency of Canada. Canadian Integrated Program for Antimicrobial Resistance Surveillance (CIPARS), 2013, Annual Report. 2013. Ottawa, Ontario: Public Health Agency of Canada, 2015 (http://www.phac-aspc.gc.ca/cipars-picra/2012/assets/ pdf/HP2-4-2012-1-eng.pdf). Accessed 18 July 2017.

35. U.S. Food and Drug Administration NARMS (NARMS). NARMS Integrated Report: 2012-2013. The National Antimicrobial Resistance Monitoring 
System. Laurel, MD: U.S. Department of Health and Human Services, FDA, 2013.

36. Vieira AR, Collignon P, Aarestrup FM. Association between antimicrobial resistance in Escherichia coli isolates from food animals and bloodstream isolates from humans in Europe: an ecological study. Foodborne Pathogens and Disease 2011; 8: 1295.

37. Yamamoto S, et al. Genetic evidence supporting the fecal-perineal-urethral hypothesis in cystitis caused by Escherichia coli. Journal of Urology 1997; 157: 1127-1129. 